\title{
A 90 años de la aparición del colectivo. Reflexiones sobre la participación del Estado en un senvicio público esencial en la Región Metropolitana de Buenos Aires (1928-2018)
}

\author{
90 years since the appearance of the bus. Reflections on State participation in an \\ essential public service in the Metropolitan Region of Buenos Aires (1928-2018)
}

\author{
Verónica Pérez \\ veronikaperez@gmail.com \\ Universidad Nacional de San Martín-CONICET, \\ Argentina
}

Recepción: 17 Octubre 2019

Aprobación: 15 Febrero 2020

Publicación: 01 Marzo 202

Cita sugerida: Pérez, V. (2021). A 90 años de la aparición del colectivo. Reflexiones sobre la participación del Estado en un servicio público esencial en la Región Metropolitana de Buenos Aires. Sociohistórica, 47, e119. https://doi.org/10.24215/18521606e119
Resumen: El artículo aborda el modo como se ha desarrollado el sistema de prestación del autotransporte público colectivo de pasajeros en la Región Metropolitana de Buenos Aires, desde inicios del siglo XX a la actualidad. El eje del análisis está puesto en identificar los factores intervinientes en el derrotero de la oferta de servicios, poniendo el foco en la orientación del Estado y sus resultantes para la movilidad de la región. Para su realización, se relevaron las principales normas gubernamentales que tuvieron impacto en el mercado bajo análisis y se efectuaron entrevistas a informantes clave. En lo que refiere al período post-2000, se analizó una base de datos en la que se registran todas las empresas prestadoras en los años 2000, 2009 y 2018, lo que permitió establecer cambios en la configuración de la oferta de los servicios. Todo el estudio fue complementado con estudios específicos sobre la temática.

Palabras clave: Colectivos, Estado, Oferta, Movilidad.

Abstract: The article deals with the way in which the system of public bus of the Metropolitan Region of Buenos Aires has been developed, from the beginning of the 20th century to the present. The focus of the analysis is to identify the intervening factors in the course of the supply of services, focusing on the orientation of the State and its results for the mobility of the region. For the preparation of the study we proceeded to relevad the main government regulations that had impact on the market under analysis, and interviews with key informants were addressed. With respect to the period after 2000, a database was analyzed with all the companies that provided services in the years 2000, 2009 and 2018, which allowed to register changes in the configuration of the offer. The entire study was complemented with specific studies on the subject.

Keywords: Bus, State, Transport offer, Mobility. 


\section{INTRODUCCIÓN}

El presente artículo aborda el modo como se ha desarrollado el sistema de prestación de autotransporte público colectivo de pasajeros en la Región Metropolitana de Buenos Aires (RMBA), coloquialmente denominado colectivo en la Argentina, desde inicios del siglo XX a la actualidad. El eje del análisis está puesto en identificar los factores intervinientes en el derrotero de la oferta de los servicios, poniendo el foco en la orientación del Estado en este sector de actividad y su resultante en las condiciones de movilidad de los habitantes de la región.

Desde su aparición como opción de movilidad para la población metropolitana, el colectivo fue ganando adeptos hasta convertirse en el principal modo de transporte público, seguido muy de lejos por el tren y el subte. En la actualidad, la RMBA tiene una de las redes de colectivos más grandes del mundo, sólo superada por el Distrito Federal de México y por Pekín. Transporta 11.8 millones de pasajeros por día, que representan el $80 \%$ de los viajes que se realizan en transporte público (Agencia de Transporte Metropolitano, 2019). Los guarismos evidencian el rol nodal que el colectivo tiene para la reproducción material de la sociedad, en tanto el viaje al trabajo sigue siendo el principal motivo de su uso, sin desmedro del cuidado de la salud y el desarrollo de la vida social en sus múltiples aristas. Sin embargo, pese a erigirse en un servicio esencial del que depende el desarrollo social y material de la sociedad, ${ }^{1}$ débiles han sido los intentos gubernamentales por regular su oferta, desde una perspectiva que atienda integralmente a las necesidades de movilidad de la población.

Las preguntas que guían el trabajo son ¿cómo se ha desarrollado la oferta de los servicios a lo largo de estos más de 90 años? ¿Cuál ha sido el rol del Estado en la definición de las condiciones de prestación y cobertura de la oferta? :Qué impactos ha tenido su intervención, en términos de la accesibilidad y calidad de los servicios, para los habitantes de la región?

La hipótesis rectora del trabajo sostiene que, así como sucede con otros ámbitos de carácter mercantil, en la historia del autotransporte público colectivo de pasajeros difícilmente se pueda afirmar que el mercado se haya desenvuelto al margen del Estado; tanto por acción como por omisión, éste ha tenido un rol destacado en la configuración de su oferta.

Aunque en sus inicios el taxi-colectivo surgió autonomizado plenamente de la intervención estatal, su rápido crecimiento y progresiva consolidación como servicio público propiciaron el desarrollo de sucesivas regulaciones que de manera creciente fueron abordando diversos aspectos de su prestación. Sin embargo, uno de los signos distintivos del desenvolvimiento del sector radica en que la orientación del Estado no se basó en una mirada integral de la movilidad, sino que las disposiciones gubernamentales más bien fueron la resultante de la emergencia de dificultades específicas que iban surgiendo a medida que el colectivo se expandía, como también de la demanda de diversos grupos de interés que se veían amenazados por su rápido crecimiento. Llegados al siglo XXI y cumplidos 90 años de su nacimiento, una mirada retrospectiva sobre el derrotero de este transporte esencial arroja algunas enseñanzas y puntos críticos a considerar de cara a la construcción de una movilidad inclusiva y sostenible para quienes nos movemos en la gran ciudad.

En el primer apartado se aborda brevemente el nacimiento del colectivo como opción de movilidad para la población metropolitana de Buenos Aires, hasta su consolidación como modo principal entre los existentes de transporte público colectivo, en los albores de la década del 70. Seguidamente, se aborda un período de progresiva intervención del Estado en la actividad, que tendrá como punto de inflexión la crisis económica de 2001/2002. En ese momento se implementa un conjunto de políticas que buscan, en el marco de una profunda crisis económica, política y social, mantener el delicado equilibrio entre rentabilidad empresaria y accesibilidad económica de los servicios, que con ajustes y reacomodamientos perdura hasta nuestros días. En el tercer apartado, se analizan las transformaciones operadas en el siglo XXI en el sector, cuando el Estado se erige en principal sostenedor de la actividad, identificando los desafíos actuales emergentes de esta sinuosa historia. Finalmente, se proponen algunas reflexiones que, lejos de buscar establecer conclusiones cerradas, abren nuevos interrogantes orientados a comprender la historia del colectivo en el territorio bajo estudio. 
Para la elaboración de este artículo se realizó un relevamiento de las principales normas gubernamentales (leyes, decretos y resoluciones) que tuvieron impacto en la configuración de la oferta de los servicios. Asimismo, se efectuaron entrevistas a informantes clave: empresarios, decisores públicos e historiadores del sector. En lo que se refiere al período post-2000, se analizó una base de datos de elaboración propia, ${ }^{2}$ en la que se registran todas las empresas prestadoras de servicios en la región, en los años 2000, 2009 y 2018, lo que permitió establecer cambios en su oferta. La base contiene datos de razón social, grupo económico, cámara empresaria, cantidad de vehículos y pasajeros transportados. Todo el estudio fue complementado con estudios específicos sobre la temática, los cuales se referencian a lo largo del trabajo.

\section{El NACIMiento DEL COLECTIVO}

Desde su aparición y hasta la actualidad, el autotransporte colectivo de pasajeros (APP) ha sufrido diversas transformaciones, tanto vehiculares como en las formas sociales bajo las cuales se ha organizado su prestación. En un péndulo que fue de lo privado a lo estatal y a lo privado otra vez, no sin hibridarse con distintas intensidades según los períodos, hoy tenemos un sistema íntegramente prestado por empresas privadas, aunque regulado por el Estado por su carácter de servicio público.

Los primeros servicios de ómnibus, los cuales no deben confundirse con la génesis del colectivo, aparecieron a inicios de la segunda década del siglo XX. En el mes de agosto de 1922 se inauguró la línea A, con recorrido entre Plaza Constitución y Plaza de Mayo y estación Retiro, perteneciente a la empresa Auto-Ómnibus Metropolitano. En ese entonces comenzó a operar un servicio realmente efectivo y continuado en la Capital Federal. La empresa prosperó y paulatinamente fue incorporando nuevos coches y ampliando el tamaño de las unidades, hasta alcanzar el número de 22 pasajeros sentados y colocados en el sentido de la marcha de los vehículos. Pronto aparecieron nuevas empresas, como la Italo-Argentina, la Fitipaldi y la Progreso Argentino, y otras en los suburbios que cubrieron zonas carentes de servicios tranviarios. El 13 de diciembre de 1923 se aprobó la Ordenanza General sobre servicios de ómnibus y en enero de 1924 ya había en la Capital Federal 30 empresas en explotación con más de 40 líneas (Ruiz Díaz, 2003).

Durante la década del 20, el servicio de ómnibus evolucionó en cantidad y tecnología, y aquellos que circulaban por las zonas céntricas de la ciudad se erigieron en una fuerte competencia para las empresas tranviarias, que comenzaron a presionar al gobierno local. Ruiz Díaz et al. (2008) sostienen que en esta dirección debe interpretarse la sanción de una ordenanza mediante la cual la municipalidad obligaba a las empresas de ómnibus a cambiar los neumáticos de sus vehículos por otros con características específicas y que no se producían en el país. ${ }^{3}$ Dicha disposición implicó un importante perjuicio económico para las empresas de ómnibus, que debieron importarlos.

No obstante, y pese a la hipotética porosidad del gobierno local frente a las demandas de los tranviarios, el rápido desarrollo del ómnibus en estos primeros años de su existencia y su superioridad competitiva frente a otros modos coadyuvaron a que algunas empresas de tranvías decidieran participar del nuevo sistema. ${ }^{4}$ Sin embargo, a poco de haber sido adquiridas, las líneas de ómnibus comenzaban a disminuir sus servicios e incluso llegaron al cese total. Dicha constatación llevó a considerar que las acciones de los tranviarios tenían por verdadero objetivo eliminar la competencia (Ruiz Díaz et al., 2008), por vía de un comportamiento predatorio que buscaba eliminar al antagonista.

Pese a disposiciones gubernamentales que favorecieron el desarrollo del tranvía, la Compañía AngloArgentina, principal propietaria del sistema tranviario, siguió acusando a la Municipalidad de tener un trato preferencial con las empresas de ómnibus. Consideraba que se debía "fomentar el ómnibus únicamente como medio de transporte complementario y no competidor o sustituidor (...) a cargo de una Empresa responsable de los transportes coordinados". 5 Tuvo que esperar casi 10 años para que el deseo se convirtiese en realidad. 
Hacia fines de la década, el mercado de transporte colectivo de pasajeros en la región dio a luz un nuevo competidor. También afectado por la progresiva atracción de la demanda que significaba el ómnibus para ese entonces, y en el marco de una crisis económica general, los propietarios de taxis se organizaron y en 1928 aparecieron en las calles de Buenos Aires los primeros taxis-colectivos. ${ }^{6} \mathrm{Su}$ surgimiento puso fin a la posibilidad de que el ómnibus se consolidara como sistema de transporte para la región (Krantzer y Sánchez, 1993 y 1994).

Con tarifas superiores a los ómnibus y tranvías, pero más bajas que los servicios normales de taxis y que se pagaban al bajar del vehículo, los taxis-colectivos trasladaban en sus inicios hasta 5 pasajeros, con frecuencias de 4 minutos, cubriendo diversos recorridos. El éxito del nuevo sistema de autotransporte propició que ya en la primera semana se establecieran numerosas líneas y que progresivamente las cabinas, gracias al ingenio de los mecánicos y carroceros locales, fueran ampliando su capacidad.

Los comienzos de este modo de transporte se caracterizaron por la ausencia total de regulación y control por parte de las autoridades gubernamentales. Autonomizados plenamente de la intervención del poder público, los dueños de taxis se expandieron y parasitaron las trazas tranviarias, de las que extrajeron sus números de línea, el cual se autoasignaban copiando el correspondiente a la línea de tranvía y a veces también el de las líneas de ómnibus, con la que competían. También, acompañando la demanda de los pasajeros establecían libremente las modificaciones de sus recorridos y la incorporación de vehículos. A cuatro años de su aparición ya había cerca de 70 líneas (Ruiz Díaz, 2003).

El rápido crecimiento motorizó la intervención de la Municipalidad de la Ciudad de Buenos Aires, que en 1932 reglamentó el servicio de colectivos y comenzó a habilitar legalmente las líneas, otorgándoles una numeración propia. También estableció tamaños máximos, lo que dio lugar a la aparición de vehículos especialmente carrozados como colectivos, con capacidades progresivamente más cercanas a las que conocemos hoy. Sin embargo, no intervino en la regulación tarifaria ni les impuso restricciones que regían para los demás sistemas.

Ya para ese entonces los ómnibus se diferenciaban claramente de los colectivos, tanto en sus características vehiculares como en la estructura empresaria que sustentaba su prestación. Mientras los primeros eran coches de mayor tamaño, cuyos servicios eran prestados generalmente por compañías cuya propiedad correspondía a uno o a pocos propietarios económicamente fuertes, ${ }^{7}$ la forma social mediante la cual se organizaba la prestación del servicio de colectivos era la sociedad de componentes. En esta estructura económica, cada línea estaba compuesta por varias unidades y los mismos choferes eran dueños de un coche o de una parte de este. En cuanto a su tamaño, las líneas tenían en promedio 40 coches por recorrido y un número similar de empresarios.

Hacia 1936, el mercado de APP de Buenos Aires se encontraba estructurado por 62 empresas de colectivos, que nucleaban a 2.022 socios que operaban 62 líneas, mientras que el servicio de ómnibus se conformaba por 53 empresas que incluían 108 socios, con control sobre 75 líneas. En algunos casos, un grupo de inversores aportaba activos (vehículos) y era responsable de su operación, haciéndose cargo de los costos e ingresos que tal activo generaba (Krantzer y Sánchez, 1994).

La prestación del servicio de colectivos se realizaba mediante organizaciones económicas informales que servían esencialmente para la reproducción social familiar, a veces ampliada. Esta clase de organización acarreaba diversas clases de conflictos, algunos de carácter económico como el destino de las ganancias, pero otros de raigambre afectiva propios de las relaciones intrafamiliares.

La oferta de transporte en la RMBA fue creciendo de manera desordenada, acompañada de un proceso de creciente diferenciación al interior del autotransporte colectivo de pasajeros (ómnibus y colectivos) y entre este y los modos guiados, tanto en lo referido a las formas de propiedad como al tipo de regulación a la que estaban sujetos. En dicho marco, en 1936 la Municipalidad de la Capital Federal dispuso no conceder nuevos permisos para líneas de transporte colectivo de pasajeros (Ruiz Díaz, 2003). 
La tendencia con la que se había desenvuelto el mercado llegó a su fin cuando a mediados de la década del 30, por medio de la ley 12311, se creó la Corporación de Transportes de la Ciudad de Buenos Aires (C.T.C.B.A.) mediante una concesión cuasi-monopólica y por un período de 56 años, ${ }^{8}$ con el objeto de centralizar la oferta de servicios en la Ciudad de Buenos Aires y entre esta y los partidos aledaños. La disposición obligaba a todas las compañías (exceptuando los ferrocarriles) a entregar la totalidad de sus bienes y permisos a la nueva empresa, a cambio deacciones de esta última o, de no aceptar esta forma de pago, recibir parte o la totalidad en efectivo. ${ }^{9}$ El Estado aportaba como capital las deudas que tenía con las empresas y se erigía como garante del financiamiento necesario para adquirir los activos de quienes no quisieran incorporase como accionistas.

En el directorio de la empresa tendrían representación el gobierno nacional, el municipal y, en función de la cantidad de bienes e inversiones que aportaran, las compañías de tranvías, subterráneos, ómnibus y colectivos. Esta situación otorgaba, por su mayor poder económico, una posición de privilegio a la Compañía Anglo-Argentina de tranvías. No obstante, la puesta en funciones de la Corporación fue muy lenta y estuvo atravesada por diversos conflictos de intereses que resultaban en marchas y contramarchas para su implementación. La empresa comenzó a gestionar efectivamente en el año 1939. ${ }^{10}$

El proceso de traspaso no se desarrolló sin tensiones. Las primeras empresas en ingresar a la Corporación fueron las tranviarias, las de ómnibus subsidiarias de ellas y los subterráneos, que lo hicieron voluntariamente y sin pedir dinero en efectivo por la entrega de sus bienes. El resto de las empresas de ómnibus que se incorporaron lo hicieron con cierto retraso, unas vendieron y en algunos casos el Estado incautó los vehículos. Pero los empresarios colectiveros se negaron a ingresar, fueron perseguidos y paulatinamente dejaron de circular por la ciudad (Krantzer y Sánchez, 1994), aunque no sin protagonizar una larga lucha. En esta dirección, el 4 de septiembre de 1942 se inició una importantísima huelga de colectiveros que resistían la expropiación de sus vehículos. Fue levantada a los 12 días pero el fracaso de las negociaciones con el gobierno llevó a un nuevo cese de actividades, que esta vez se extendió por un período de casi 4 meses. La resultante del conflicto fue variable, y hubo colectiveros que escaparon con sus coches a la provincia de Buenos Aires, donde gozaban de inmunidad. ${ }^{11}$

Interesa resaltar la hibridación que se produjo en el lapso entre 1939 y 1951, año en el que la C.T.B.A. fue licitada en subasta internacional. La importante resistencia que los colectiveros opusieron a la expropiación de sus únicas fuentes de reproducción material decantó en una diversificación de formas de propiedad y de prestación de las líneas de colectivos. Por un lado, estaban las líneas de propiedad estatal, dependientes de la Corporación. Por otro, emergieron las que quedaron en manos privadas, operando mediante un "convenio de tenencia" a cuenta y riesgo de sus dueños, por un plazo que inicialmente sería corto pero que, con el cambio de gobierno en 1943 y la disposición de interrumpir las expropiaciones, terminó extendiéndose por muchos años.

La breve pero controvertida historia de la Corporación merece un artículo aparte. Sólo interesa resaltar aquí que su derrotero se vio fuertemente atravesado por los efectos que la Segunda Guerra Mundial tuvo para la economía mundial y regional en particular y por las propias lógicas de desarrollo de la empresa pública en Argentina. Hasta el cambio de gobierno, la Corporación siguió incautando vehículos al tiempo que creaba nuevas líneas. Asimismo, con el fin de la guerra pudo importar coches para cubrir las deficiencias de los servicios e introdujo algunas modificaciones en la organización de las prestaciones. También creó el sistema de Trolebuses en 1948. ${ }^{12}$ La terminación de la contienda mundial generó a su vez condiciones favorables para que los transportistas privados fuesen renovando sus unidades, lo que permitió que paulatinamente los colectivos de once asientos fueran reemplazados por micro-ómnibus de 16 a 20 asientos. ${ }^{13}$

El llamado a licitación internacional para adjudicar los servicios y bienes de la C.T.C.B.A no tuvo ningún oferente. Por fuerza de los hechos, el Estado nacional terminó haciéndose cargo de la empresa y conformó la Administración General de Transportes de Buenos Aires (T.B.A), dependiente de la Empresa Nacional 
de Transportes, de propiedad estatal. ${ }^{14}$ Durante la gestión de T.B.A, y en el marco de la crisis de la empresa estatal $^{15}$, en el año 1955 se procedió a la transferencia de 68 líneas de colectivos al personal que las operaba. Así comenzó un lento pero progresivo proceso de reprivatización de las líneas de colectivos, imbricado en uno más amplio de privatización de la empresa de Transportes de Buenos Aires. Esta se disolvió por decreto No 1347, del año 1962 y se dispuso la adjudicación mediante licitación pública a entes privados de los distintos servicios, exceptuando el subterráneo.

En el marco de este proceso, en 1961 (Decreto № 3106) se estableció el régimen de otorgamiento de permisos definitivos para la prestación de servicios en la Capital Federal y la Región Metropolitana. Si bien la Secretaría de Estado de Transporte conservaba sus facultades de regular dentro de la Capital Federal el servicio de las líneas de APP (recorridos, tarifas, horarios y habilitación del parque móvil), las decisiones emanadas de organismos provinciales y municipales generaban desacoples e incoherencias de políticas. Este decreto tuvo por intención resolver las anomalías pues sometió los servicios que circularan dentro de la Capital Federal, o unieran esta con la provincia, al ámbito de la jurisdicción nacional. Sin embargo, a pocos años de su vigencia fue suspendido bajo el argumento de que se debía contar, previo a su ordenamiento, de un plan racional de servicios (Resolución SST No 198/65). (Estudio Preliminar de Transporte de la RMBA, Tomo 1, 1972, p.176).

También en 1961 se transfirieron 49 líneas de ómnibus a capitales privados y la Secretaría de Transporte decidió el alargue en el recorrido de varias líneas, permitiéndoles en algunos casos el ingreso a la capital y la penetración en el centro de otros partidos de Buenos Aires, en una política de fuerte competitividad con los modos guiados como el ferrocarril suburbano, el subterráneo y el tranvía. En 1962 se reemplazaron todos los tranvías por ómnibus privados y un año después, todos los trolebuses por ómnibus y $\operatorname{colectivos}^{16}$, y se dio mayor preeminencia a estos últimos. En este período también se numeraron las líneas: 1 a 199 para la Jurisdicción Nacional; 200 a 499 para las de provincia de Buenos Aires y 500 en adelante para los municipios. En 1963, la Secretaría de Transporte de la Nación dispuso no acordar permisos para nuevas líneas de transporte público de pasajeros de su jurisdicción en el Área Metropolitana de Buenos Aires. El último permiso otorgado había sido en 1962 a la línea 297 (actual 97). Desde entonces, y hasta el año 1978, no se concedió ningún otro ${ }^{17}$ (Ruiz Díaz, 2003, p. 37).

Ya en los albores de la década del 70, y continuando con la iniciativa de ordenar el sistema, el Estado estableció los mecanismos que debían seguir las empresas de APP para pedir modificaciones de recorridos o de otros parámetros operativos. Mediante Resolución de la Secretaría de Transporte y Obras Púbicas (SETOP) No 44/1969, se estableció que las empresas debían realizar el pedido a la Secretaría de Transporte y esta implementaría los trabajos necesarios para establecer si había "necesidad pública" y "afectación a otras líneas". Esta última condición se habilitaba si otras líneas presentaban reparos a la modificación solicitada. Pero los pedidos sin contestar se fueron acumulando, evidencia no sólo de la falta de capacidades estatales para hacer frente a las solicitudes emanadas de dicha resolución, sino también de la informalidad de un mecanismo que habilitaba la emergencia de diversos conflictos de intereses.

En esta dirección, un funcionario de la Dirección Nacional de Transporte que en ese entonces se desempeñaba en el organismo afirmaba respecto de la referida norma:

\footnotetext{
No era nada estructural ni orgánico. Cada empresa que quería un nuevo recorrido o prolongación presentaba la solicitud. No existía control de cumplimiento de obligaciones (...) No tenía exigencia de información mínima a suministrar para demostrar conveniencia del recorrido, la factibilidad de que la empresa lo atendiera, etc. Era todo mercado libre. (...) Los pedidos se demoraban mucho porque después estaban las instancias del trámite administrativo, la posibilidad de impugnaciones por parte de los que se consideraban afectados. Ahí era todo un manejo político, porque estaba también la actitud de la Cámara (...) además de los manejos y las influencias políticas. En el caso de las [líneas] urbanas, los políticos y funcionarios de turno, por razones de amistad o cosas, llamaban al Secretario de Transporte [para que interviniera].
}

Debieron pasar 16 años hasta que se implantara un mecanismo tendiente a establecer un proceso claramente normado para pedir modificaciones en las condiciones de la oferta de los servicios. 
Los años 60 parieron la gran transformación del sistema de transporte público colectivo en la Región, y desde entonces y hasta nuestros días se consolidó el colectivo como sistema dominante de la movilidad metropolitana. A partir de este momento, el sector quedaría vinculado en forma decisiva al desempeño individual de cada una de las empresas y al segmento de mercado que le tocara explotar (Krantzer y Sánchez, 1994).

\section{LA CONSOLIDACIÓN DEL COLECTIVO}

En dirección a analizar la orientación del Estado luego de la liquidación de la empresa estatal de transporte, se tomó una serie de medidas tendientes a organizar la oferta de los servicios; sin embargo, obstáculos derivados en parte del desacople entre metas y medios (capacidades estatales) supusieron la consolidación de comportamientos empresarios que continuaron desenvolviéndose con relativa independencia del poder público y, también, el afianzamiento de una representación generalizada acerca de que el conocimiento del campo estaba del lado de los privados, creencia que se profundizaría en los años subsiguientes.

Durante la década del 70 la injerencia estatal en el sector fue prácticamente inexistente, aunque las pocas disposiciones emanadas repercutieron en la configuración de la oferta. En este decenio se dictaron las primeras normas regulatorias de la actividad, que obligaban a los operadores a constituirse en personas jurídicas bajo el Código de Comercio (Sociedad Anónima, de Responsabilidad Limitada o cooperativa), si bien, como se mencionó, a fines de los 70 la mayoría de las empresas conservaba de hecho las características organizacionales de sociedad de componentes, ${ }^{18}$ con un promedio de un socio por vehículo, aunque con socios propietarios de varios vehículos (diez o más) y vehículos pertenecientes a varios socios. El elevado número de componentes era típico de estas sociedades y la mitad de ellos trabajaban como conductores.

Este tipo de organización promovía el florecimiento de fuertes conflictos internos entre los socios de las empresas, principalmente en lo relativo al control de la recaudación, que estaba en manos del socio componente, el cual debía aportar a fin de mes lo correspondiente a gastos comunes a la empresa. La participación de los socios en la gestión también ocasionaba tensiones, pues la sociedad anónima como entidad reguladora de una comunidad de intereses constituía, las más de las veces, una cáscara vacía. La segmentación de la responsabilidad sobre la gestión de los coches, la provisión de insumos básicos, la contratación de personal y elección de mecánicos componían un sistema organizado sobre la base de la sumatoria de decisiones individuales, que "en aquellas empresas que no habían conseguido un régimen de procedimientos propios, eran una máquina de producir conflictos". ${ }^{19}$ En esta dirección, y según relata un entrevistado, el Departamento de Pasajeros de la Dirección de Transporte Terrestre, del cual dependía todo el transporte urbano e interurbano, era muy activo en resolver conflictos internos entre líneas y empresas y en lidiar con presiones políticas de todo tipo. ${ }^{20}$

Hacia 1970 existían 310 líneas en el AMBA (que originaban 743 ramales distintos) y una tercera parte de ellas correspondía a empresas que explotaban más de dos y hasta nueve líneas. Los vehículos de jurisdicción nacional representaban el $74 \%$ de la oferta (10.420 vehículos), mientras que los de jurisdicción provincial, el $12 \%$ del total (aproximadamente 1.800 vehículos) y los municipales, el 14\% (1.930) (Estudio Preliminar de Transporte de la RMBA, Tomo 1, p. 176). Cada una de estas jurisdicciones regulaba aspectos tarifarios y técnicos de la prestación de los servicios en forma autónoma, situación que perdura hasta nuestros días, lo que provoca una heterogeneidad de situaciones con consecuencias dispares en las condiciones de movilidad de la región y un obstáculo a la racionalización de la oferta.

Un rol más activo en materia de calidad de los servicios asumió la SETOP cuando en 1978, por resolución No 33, obligó a las empresas a renovar los vehículos que tuvieran más de 10 años de antigüedad. Dicha disposición pudo haber contribuido a la desaparición de empresas, que según datos de la CNRT (2019) pasaron de 149 a 134 entre dicho año y 1983: desaparecieron 33 líneas. No obstante, un proceso de 
concentración de la oferta, principalmente mediante el mecanismo de entropía (reducción en el número de socios por empresa), ya venía desarrollándose desde inicios de la década del 70 y así continuaría en los años sucesivos, aunque con oleadas de distintas características e intensidades.

Luego de la revolución de los años 60, la veintena de años siguientes gozaron de una relativa calma en cuanto a disposiciones y reordenamientos. Es un lapso extendido en el que prácticamente no se registran intervenciones estatales en el sector, pero también en el que se ensaya un primer intento por desarrollar una mirada integral de la movilidad de la Región a partir del pedido, del Ministerio de Obras y Servicios Públicos, de un Estudio Preliminar de Transporte de la RMBA. Este Estudio se completó en 1972. Sin embargo, las recomendaciones de política emanadas de este importante trabajo nunca fueron llevadas a la práctica y quedaron como letra muerta en papel de oro para estudiosos sobre la temática. El rol planificador del sector público no volvería a tener presencia sino hasta los años 2009-2010, cuando se realizó una capacitación a jóvenes profesionales y se elaboró un "Plan Federal de Transporte", publicado en el año 2015. Como en el caso anterior, nada de lo sugerido se tuvo en cuenta.

En los años 80 se retomó débilmente la iniciativa de dar un poco de orden al sistema ya que, derivados de la disposición SETOP N44/69, se habían acumulado cientos de pedidos de modificaciones de recorridos sin resolver. Pero la disposición profundizó la enajenación de la iniciativa estatal a favor de los privados, al transferirles la responsabilidad de realizar los estudios necesarios para viabilizar las modificaciones solicitadas. El proceso normado en la Resolución MOSP No 237 del año 1985, establecía que el interesado debía realizar un estudio por encuesta que verificara la existencia de una "necesidad pública" de la modificación solicitada y publicarlo en distintos medios de prensa para conocimiento del resto de las empresas, las cuales podían argumentar "afectación de intereses". Pero el resultado fue parcial. Entre 1985 y mediados de la década del 90 se aprobaron alrededor de 30 pedidos de modificaciones nacidas al amparo de la Resolución No 237; entre 1999 y 2001, durante el corto período de gobierno de la Alianza, apenas dos, mientras que durante los 12 años de gestión de los gobiernos del Frente para la Victoria (2003-2015), ninguno. ${ }^{21}$ La brecha entre pedidos de modificación y respuestas del sector público se fue ampliando progresivamente.

En este contexto, la entrada de nuevos operadores a la actividad no asumió carácter competitivo vía licitaciones sino que las líneas que caducaban se asignaban a determinadas empresas, en general con cierta familiaridad territorial, y en especial, por los activos donde guardar los vehículos. La licitación como mecanismo de ingreso fue, hasta hoy día, la excepción y no la norma: no más de 25 líneas de jurisdicción nacional se licitaron, en el AMBA, a lo largo de la era del colectivo hasta la actualidad. ${ }^{22}$

Frente a la baja fiscalización estatal, la dinámica de control quedó centrada en las acciones empresarias. Estas desenvolvieron un mecanismo de vigilancia cruzada entre empresas mediante el cual los desvíos de recorridos no autorizados, o cualquier violación a las normas que pudiera afectar la rentabilidad o el funcionamiento esperado de alguna, era rápidamente denunciado a la autoridad. Asimismo, en tanto la distribución de ingresos entre los socios estaba influida por la venta de boletos, la competencia ayudaba a mantener la regularidad de las prestaciones. Como contracara, se consolidó la enajenación por parte del Estado de sus funciones de fiscalización, ${ }^{23}$ de la misma manera que tenía cedido el rol proactivo en materia de modificación en la red a través de las normas mencionadas.

Llegamos así a la década de los 90, la cual constituye un punto de inflexión para el sistema de transporte público de pasajeros tal como se venía desarrollando. La concesión a operadores privados de los sistemas guiados y las disposiciones regulatorias dirigidas a reordenar el APP dieron lugar a un fuerte proceso de concentración, a la configuración de nuevos entramados de relaciones entre Estado y empresarios, y también ampliaron la densidad de las relaciones intraempresarios del campo del transporte, como había sucedido en la década del 20 cuando los tranviarios avanzaron hacia el sector del autotransporte de pasajeros, aunque no exactamente con la misma orientación.

En este último sentido, algunas líneas de colectivos pasaron a ser operadas por empresas ferroviarias ${ }^{24}$ y en los consorcios que se hicieron cargo de los ferrocarriles tuvieron importante presencia empresas de 
APP (Gutiérrez, 2004 y Pérez, 2012 y 2013). Si bien en la mayoría de los concesionarios la presencia de autotransportistas fue efímera, subsumida a la celeridad de los cambios en la composición accionaria de los grupos ferroviarios, hacia el final de los años 90 COMETRANS, consorcio liderado por uno de los más importantes grupos de autotransporte de la RMBA, pasó a controlar el $100 \%$ de las acciones de T.B.A (líneas ferroviarias Sarmiento y Mitre).

La disposición más importante del período, en términos del impacto que tuvo para el ámbito del APP, fue el Decreto 656/94. La norma dio paso a la regularización del sector mediante un llamado a repermisionamiento que implicaba para las empresas el cumplimiento de un conjunto de obligaciones de muy difícil observancia para algunas de ellas. Entre las condiciones para participar del llamado se destacaba la necesidad de contar con espacios para el guardado del parque móvil, la demostración de solidez patrimonial, la incorporación de innovaciones tecnológicas, la contratación de seguros de riesgo y la acreditación del pago de la Tasa Nacional de Fiscalización del Transporte. También se incluían obligaciones previsionales e impositivas como prerrequisito para la obtención del permiso. Estos serían otorgados por 10 años, con renovación automática por iguales períodos.

En cuanto al criterio de tarificación de los servicios, se siguió basando en un costo medio de producción y en una demanda promedio que posibilitó la obtención de rentabilidades diferenciales y, por ende, posiciones de privilegio a las empresas mejor ubicadas en el reparto del mercado. La configuración de plusganancias o rentas regulatorias (Gutiérrez, 2016), la estabilización de la conformación interna de los grupos empresarios y el quiebre de algunas empresas que no pudieron afrontar los nuevos requerimientos de capital colaboraron en la consolidación de un fuerte proceso de concentración. El rasgo distintivo del período fue el crecimiento de los grupos empresarios que, vía fusiones y absorciones, se convirtieron en la principal forma organizacional del mercado de APP.

Las resoluciones dictadas por la Secretaría de Transporte hacia fines de los 90 (302 y 445, ambas del año 1999) dieron un marco jurídico y acentuaron el proceso de concentración al habilitar la transformación de las empresas operadoras, orientando su integración mediante acuerdos de gerenciamiento, colaboración empresarial y fusiones societarias, entre otras formas.

En términos de control y fiscalización, en sintonía con el clima de época por primera vez se creó un órgano de fiscalización del transporte automotor (Decreto No 104/93). La Comisión Nacional de Transporte Automotor (CoNTA) tuvo una corta vida. En el año 1996 fue absorbida por un nuevo órgano de control con injerencia en todo el sector transporte terrestre de Jurisdicción Nacional: Comisión Nacional de Regulación del Transporte (CNRT). Bajo el nuevo paradigma, emergente de una nueva concepción de regulación resultante del radical proceso de privatización de empresas de bienes y servicios públicos, la orientación estatal vía regulaciones no cubriría simplemente aspectos de tarificación y defensa de la competencia (visión neoclásica), sino también temas vinculados a la cobertura (universalización y tarifas accesibles), defensa de los derechos de los usuarios y sustentabilidad del servicio a mediano y largo plazo. El locus institucional para tales potestades serían los flamantes entes de regulación (Nahón y Bonofiglio, 2007).

La CNRT estuvo exenta de las tareas de regulación en sentido clásico (fijación de tarifas, modificaciones de parámetros operativos, entre otros), potestad que quedó bajo la órbita de la Secretaría de Transporte. En cuanto a su rol de control y fiscalización, durante este período se caracterizó por una débil performance, derivada de la falta de capacidades estatales (principalmente de recursos humanos y tecnológicos) que le permitieran llevar adelante las funciones para las cuales había sido creada.

Las transformaciones que tuvieron lugar en el mercado APP durante los 90 no fueron a contramano de las tendencias generales observadas en otros espacios económicos, si bien resaltan algunas diferencias. Las políticas de desregulación, privatización y apertura económica que dinamizaron el nuevo patrón de acumulación configuraron mercados más concentrados, extranjerizados y excluyentes desde el punto de vista de la accesibilidad de sus usuarios y consumidores. En el caso bajo estudio, la mayor concentración fue 
acompañada por una menor accesibilidad económica por parte de los usuarios, sostenida en el peso creciente del transporte público sobre el gasto de consumo de los hogares. ${ }^{25}$

Pero el proceso de extranjerización que tuvo una gravitación central en la dinámica económica argentina no tuvo asidero en este espacio. Aquí la concentración se produjo de manera endógena: fue protagonizada por familias que tenían una historia en el campo y principalmente por los llamados "troperos", 26 propietarios de muchos vehículos con presencia en el mercado desde hacía muchos años. Eran individuos que progresivamente fueron desarrollando una lógica de utilización del excedente más orientada a la acumulación que al consumo. En la mayoría de los casos, ellos resultaron los ganadores de la década del 90, al ser beneficiados por políticas que no necesariamente buscaban ese resultado, pero que tendieron a reforzar su poder económico.

La contracara de estas políticas fue una agudización de situaciones de vulnerabilidad entre las empresas más desfavorecidas en el reparto del mercado, que en muchos casos se extinguieron al calor del avance de las reformas.

La resultante de la década para el campo bajo estudio fue la consolidación de posiciones dominantes en una estructura de mercado que había transformado profundamente su forma original. Si la atomización del capital fue un rasgo distintivo en su origen, ello fue mutando drásticamente. Hacia fines de los años 90, el 38 $\%$ de los operadores conservaba relativamente la estructura artesanal de antaño, asumiendo el $62 \%$ restante formas más complejas (Gutiérrez, 2004).

A inicios del siglo XXI se podían identificar cuatro tipos de organizaciones: empresas monolínea (aquellas de propiedad de un solo capital accionario, con única razón social y a cargo de una única traza o línea); empresas multilínea (las que, estructuradas de igual forma que la anterior, operaban más de una línea); grupos empresarios (un mismo capital controlaba diferentes razones sociales y trazas); y uniones de grupos ( dos o más grupos empresarios unidos controlaban a su vez varias razones sociales y trazas). Según datos de Gutiérrez (2004), en los albores del siglo XXI las empresas multilínea, los grupos y las uniones de grupos controlaban el $83 \%$ de las líneas, el $84 \%$ del parque y el $82 \%$ de la recaudación.

\section{El COMIENZO DE UNA NUEVA HISTORIA}

En la Argentina, la entrada al siglo XXI se produjo en el marco de una crisis de carácter inédito en la historia del país. El modelo económico basado en la utopía de los mercados autorregulados mostraba sus peores signos de agotamiento (Basualdo, 2013). Gran parte de los marcos ordenadores de la vida en sociedad (institucionales, políticos, económicos) quedaron resquebrajados. El sector bajo estudio no quedó exento de las consecuencias de dicha situación. Entre 1991 y 2002, había perdido un $46 \%$ de pasajeros y decenas de empresas habían quebrado.

Con una pobreza que alcanzó al $51.4 \%$ de la población en junio de 2002, una indigencia del $21.9 \%$ y una tasa de desocupación del 25 \% (Lozano, 2002), el gobierno del presidente provisional Eduardo Duhalde (enero de 2002 a mayo de 2003) congeló las tarifas de servicios públicos e implementó una política de compensaciones tarifarias que marcaría el derrotero la actividad en general y del transporte público de pasajeros en particular, hasta la actualidad.

En el año 2002, mediante decreto 652, se estableció un precio diferencial del gasoil para las empresas de transporte público automotor de pasajeros, en todas las jurisdicciones. También, y por medio del mismo decreto, se creó el Sistema Integrado de Transporte Automotor (SISTAU), mediante el cual se implementaron compensaciones que cubrían la diferencia entre la tarifa técnica (surgida de las metodologías de estimación de los costos de producción) y las tarifas cobradas a los pasajeros (cuyo valor se determinó por debajo de la primera).

En sus orígenes, la distribución de los fondos del SISTAU se realizó a partir de la cantidad de vehículos de cada jurisdicción sobre la base de información enviada a la Secretaría de Transporte a través de las autoridades 
de cada provincia. La información original mostró el caos derivado del vértigo por implementar el subsidio. Por un lado, puso al descubierto el lamentable estado administrativo de las direcciones provinciales de transporte. Por otro, y en algunos casos, evidenció la intención de poder incluir en los subsidios a servicios "no públicos". ${ }^{27}$

Esta primera distribución fue rápidamente modificada (a poco más de tres meses de la primera) por otra de mayor complejidad, si bien simple: pasajeros (25\%), kilómetros recorridos (25\%) y recaudación (50 \%). Este criterio duró hasta el año 2012.

La forma de relevar la información necesaria para la distribución de los fondos del SISTAU consistió en declaraciones juradas presentadas por las empresas prestatarias de servicios de transporte urbano de pasajeros ante las autoridades provinciales o nacionales de transporte, según correspondiera. Este mecanismo fue progresivamente suplantado a partir del año 2011 cuando se implementó el sistema SUBE, ${ }^{28}$ sobre el cual se volverá más adelante.

En el año 2006 se creó, mediante el decreto No 678, el Régimen de Compensaciones Complementarias (RCC) al SISTAU, destinado a compensar el incremento de costos en los que hubieran incurrido las empresas que prestaran servicios en el ámbito geográfico de la RMBA con independencia de la jurisdicción responsable de los servicios. ${ }^{29} \mathrm{El}$ régimen $\mathrm{RCC}$ fue, desde el inicio, afrontado con fondos provenientes del Tesoro Nacional y su cálculo se basó en la diferencia entre el monto que las empresas recibían mensualmente por SISTAU y el incremento de costos que debían afrontar, priorizándose los costos de personal, de renovación del parque móvil afectado a servicios y de formación y capacitación obligatoria del personal. A partir de la sanción de esta norma, se registraron niveles de inversión y renovación de flotas muy significativas. La antigüedad promedio del parque automotor pasó de 8.3 a 5.9 años.

La importancia que asumieron los subsidios para el funcionamiento del sector y su peso creciente en las finanzas públicas constituyeron el principal anclaje para el desarrollo de numerosas críticas, entre las que destacaron tres. La primera fue la ineficiencia general de la política, ya que una tarifa más barata del transporte público no desalentó el uso del automóvil, que, como se verá más adelante, consolidó su preeminencia como opción de movilidad en la región. La segunda fue su inequidad distributiva, en tanto la mayor proporción de subsidios se concentró en la RMBA. Y finalmente, el haber funcionado como un incentivo negativo para el mejoramiento de la calidad de los servicios, ya que esta no formó parte de los cambiantes criterios que impactaron en el cálculo de las compensaciones destinadas a cada empresa. A este último aspecto se articuló una crítica adicional, basada en la atribución de un comportamiento empresario orientado casi exclusivamente a incrementar sus ganancias sobre la base de recursos estatales.

Aunque no es objeto de este trabajo discutir pormenorizadamente las posiciones adversas referidas, se torna necesario realizar algunos señalamientos que matizan las críticas aludidas y permiten comprender mejor la dinámica que asumió el sector.

En primer lugar, los subsidios al transporte de pasajeros son una política que se utiliza en la mayor parte del mundo y en muchos países ha funcionado efectivamente como un desaliento al uso del automóvil particular, el que ocasiona múltiples perjuicios al bienestar de la sociedad (altos niveles de contaminación, congestión, etc.). Sin embargo, la eficacia de la política en este sentido se relaciona también con otras acciones gubernamentales con las que se articula, como subsidios atados a indicadores de calidad (Chile) o mayores costos al uso de transporte individual (Londres), por citar algunos ejemplos. En el extremo, 99 ciudades en el mundo brindan transporte público gratuito y la experiencia internacional ha demostrado ser exitosa como desaliento al uso del autotransporte individual (Keblowski, 2018).

Asimismo, y pese a las limitantes del caso argentino, los datos disponibles permiten hacer observable un incremento relativo en el uso de los medios masivos de transporte durante el período 2007-2014, en detrimento del uso del automóvil particular. Como se muestra en la Tabla 1, el uso de modos masivos creció un $4 \%$ en dicho lapso, mientras que el uso del automóvil particular disminuyó en un $2 \%$. 
TABLA 1

Evolución de la tasa de generación de viajes por modo (1997-2007-2014)

\begin{tabular}{|l|c|c|c|}
\hline \multicolumn{1}{|c|}{ Modo } & $\mathbf{1 9 9 7}$ & $\mathbf{2 0 0 7}$ & $\mathbf{2 0 1 4}$ \\
\hline Medios masivos & $44 \%$ & $39 \%$ & $43 \%$ \\
\hline Ómnibus & $34 \%$ & $31 \%$ & $32 \%$ \\
\hline Ferrocarril & $6 \%$ & $6 \%$ & $7 \%$ \\
\hline Subterráneo & $3 \%$ & $3 \%$ & $5 \%$ \\
\hline Automóvil & $36 \%$ & $40 \%$ & $38 \%$ \\
\hline
\end{tabular}

Fuente: Elaboración propia sobre la base de datos de Müller y Kralich (2009) y estimación Müller, 2014

Respecto de la inequidad distributiva, la Región Metropolitana de Buenos Aires concentra alrededor de un tercio de la población total del país y es el núcleo principal de la actividad económica (concentra casi un $53 \%$ del PBI). En esta clave, puede matizarse el concepto de inequidad, en tanto el transporte público es utilizado principalmente por motivos laborales y población de ingresos medios y medios-bajos. Este punto también debiera ser pensado en clave de considerar el rol vital que el transporte público cumple para la dinámica social y económica de nuestras sociedades, además de su potencial como herramienta democratizadora de oportunidades.

Finalmente, y en lo referido al comportamiento empresario y sus consecuencias para la calidad de los servicios, las críticas se sustentaron principalmente en el mecanismo de cobro de los subsidios, basado en declaraciones juradas de las empresas. El argumento de mayor circulación fue que moldeó conductas empresarias unilateralmente orientadas a la maximización del subsidio con base en el sobredimensionamiento de las variables implicadas en su cálculo, principalmente la declaración de mayor cantidad de kilómetros recorridos que los efectivamente realizados. Sin embargo, la evidencia empírica disponible ha permitido constatar que, lejos de tratarse de un comportamiento generalizado de los empresarios del sector, fue desarrollado por un conjunto menor. ${ }^{30}$ Asimismo, la información volcada en las declaraciones permitió un primer acercamiento a las condiciones de funcionamiento del sector que sirvió de base para el ajuste de la política.

En este contexto, después de años de congelamiento la tarifa de colectivo fue incrementándose progresivamente ( $20 \%$ en 2008 y $23.3 \%$ en enero de 2009). Un mes más tarde, mediante el Decreto oo 84 del año 2009, se resolvió la implementación del SUBE como sistema obligatorio para el cobro de pasajes, a ser implementado en un plazo máximo de 90 días. La medida desencadenó profundas resistencias por parte de los empresarios ya que necesariamente implicaba una pérdida del control de la recaudación, la cual sería concentrada por el Estado, a través del Banco de la Nación Argentina.

También en el año 2009 se aprobó la metodología de cálculo de costos de explotación del transporte urbano y suburbano de pasajeros, con base en un estudio de la Facultad de Ciencias Económicas de la Universidad de Buenos Aires. Por primera vez en toda la historia del APP, las metodologías de cálculo de costos de explotación de las líneas de Jurisdicción Nacional fueron publicadas. Con base en ellas, en el año $2013^{31}$ se amplió la cantidad de grupos tarifarios reconociendo las diferencias de prestación de servicios en el AMBA. ${ }^{32}$

En agosto de 2012 (Res. No 66 MIyT) se dispuso un nuevo incremento de tarifas, pero esta vez, además de avanzar hacia medidas que permitieran reducir el peso de los subsidios sobre las cuentas públicas, la medida se orientó a incentivar el uso de la tarjeta SUBE como mecanismo para el pago del servicio, ${ }^{33}$ desalentando fuertemente el pago en efectivo. En el mismo año también se dispuso una tarifa diferenciada para los sectores más vulnerables de la población que abonaran su boleto con SUBE. ${ }^{34}$ En el año 2014, el nuevo sistema había 
sido completado para todos los modos de transporte y se habían implementado los sistemas de navegación y localización mediante satélites (GPS).

En términos del fortalecimiento de las capacidades estatales, la implementación del SUBE fue un hito. Por un lado, creó condiciones de posibilidad excluyentes para el diseño y ejecución de políticas de transporte más adecuadas a la realidad del sector, al tener el Estado metadata sobre los viajes realizados en la totalidad del sistema de transporte público (pasajeros, recorridos, frecuencias, etc.). Esto posibilitó un desplazamiento central del locus de conocimiento, atribuido históricamente a los empresarios y ahora posicionado del lado del sector público. Por otra parte, esta información fue fundamental para reorientar los esquemas de subsidios hacia la demanda. En esta línea puede ser pensada la profusa producción de normas referidas a los criterios del cálculo y asignación de compensaciones tarifarias, que llegaron a 34 en el período comprendido entre 2012 y 2017 . Un proceso de aprendizaje y acomodación a las condiciones reales de operación que sin duda no hubiese sido posible sin esa plataforma de conocimiento.

Cabe destacar otros efectos positivos en la movilidad metropolitana, derivados de la implementación de compensaciones basadas en información del SUBE y señalados por Domecq, Neri y Saumet (2014):

(...) la aplicación de subsidios en el transporte público también apuntala las mejoras y en muchos casos las maximiza, ya que las empresas se ven obligadas a una serie de "exigencias virtuosas" ${ }^{35}$ para mantener el beneficio (zanahoria muchísimo más eficaz que los sumarios y las multas). Por otra parte, generan un efecto colateral (con las bajas tarifas del servicio público) de cuasi eliminación del transporte ilegal ("trucho"), que es uno de los flagelos más difíciles de combatir para el organismo [CNRT].

Debido a las exigencias que supone el cobro del subsidio para las empresas, el nivel de informalidad es prácticamente nulo. $\mathrm{Al}$ respecto, un informante clave señalaba que "si toda la economía tuviera el nivel de formalidad que tienen los colectivos urbanos, el sector fiscal estaría mucho mejor" ${ }^{36}$

Finalmente, aunque no menos importante, las medidas implementadas permitieron una lenta disminución del peso de los subsidios al sector, que iniciaron una tendencia decreciente en términos reales a partir de 2011. No obstante, éste continuó siendo considerable, siendo el modo APP el que mayor crecimiento experimentó: pasó de explicar del $35.7 \%$ al 66,1 \% del monto total de subsidios al transporte entre los años 2006 y 2013 (ASAP, 2014). Cabe notar que estos niveles de dependencia de transferencias estatales en los ingresos de las empresas de transporte automotor también existen en otros países, como Estados Unidos y Reino Unido (Estupiñán et al, 2007, citado en ASAP, 2014). Por su parte, un trabajo de Gonzálvez (2016) muestra que igual situación se registra en otras ciudades del mundo. ${ }^{37}$

En lo que respecta a la configuración de la oferta, y en tanto consecuencia no buscada de la política, empresarios entrevistados señalan distorsiones derivadas de la falta de ajuste de la ecuación económica para el cálculo de las compensaciones tarifarias, que favorecían a los servicios de jurisdicción nacional por sobre los provinciales y municipales, y también la imposibilidad de muchas empresas de asumir el costo de la tecnología necesaria para el cambio de sistema. En esta dirección, las disposiciones del período arrastraron nuevas fusiones y adquisiciones, con lo que se profundizó un proceso de concentración de larga data. Entre 2009 y 2018, la cantidad de empresas pasó de 91 a 88 (la reducción fue después del 2015), pero mientras en 200940 pertenecían a grupos empresarios, en 2018 esta clase se había incrementado en 10. Mientras tanto, los grupos pasaron en igual período de 17 a 19; también se conformaron nuevas uniones entre grupos y otras desaparecieron (Pérez y Sánchez, 2019). 
TABLA 2:

Porcentaje de empresas en grupos y uniones de grupos empresarios. Años 2009 y 2018

\begin{tabular}{|r|c|c|c|}
\hline $\begin{array}{c}\text { Cantidad de grupos y porcentaje de empresas } \\
\text { en grupos }\end{array}$ & 2009 & 2018 & $\begin{array}{c}\text { Crecimiento porcentual } \\
2009-2018\end{array}$ \\
\hline Grupos & 17 & 19 & 2 \\
\hline$\%$ de empresas en grupos & $67.8 \%$ & $\mathbf{8 0 . 6} \%$ & 18.9 \\
\hline$\%$ de empresas en uniones de grupos & $18.6 \%$ & $16.1 \%$ & -13.4 \\
\hline$\%$ de empresas en UTE $\left.{ }^{*}\right)$ & $13.6 \%$ & $3.2 \%$ & -76.5 \\
\hline
\end{tabular}

Fuente: Base Empresas y empresarios de autotransporte público de pasajeros, PICTO-4803 $\left({ }^{*}\right)$ Unión Transitoria de Empresas

La tabla precedente hace visible la direccionalidad que asumen los cambios en el mercado (concentración) a la vez que la forma principal a partir de la cual se desenvuelven. Por un lado, las empresas no pertenecientes a grupos disminuyen en cantidad, y aumentan las que pasan a conformar estas formas de organización empresaria. Por otro, la forma grupo empresario, esto es, organizaciones que nuclean varias razones sociales, es la que más crece en cantidad de empresas absorbidas, comparada con otras modalidades que también se desarrollan en este mercado, como las uniones entre grupos.

En el marco de este derrotero, los grupos pasaron de controlar el $71.3 \%$ de los vehículos de jurisdicción nacional al $79.9 \%$ en el período 2009-2018, mientras que las empresas no pertenecientes a grupos disminuyeron de $28.7 \%$ a $20.1 \%$ (Base PICTO, 4803).

El cambio de gobierno en diciembre del año 2015 y las medidas implementadas en el marco de una nueva concepción de la política y de lo público significaron unas nuevas condiciones de equilibrio para el desenvolvimiento del sector, que afectaron profundamente la performance de las empresas, imbricadas en un contexto económico general caracterizado por una progresiva recesión económica.

Una de las principales políticas desarrolladas por el gobierno de la Alianza Cambiemos (2015-2019), en tanto marcó fuertemente el derrotero de la gestión, fue el reajuste entre tarifas y subsidios aplicado en todos los servicios públicos de infraestructura económica, con resultados variables. En el caso del sector de APP, y bajo el argumento de hacer sustentables los servicios, el incremento tarifario entre marzo de 2015 y el mismo mes de 2019 alcanzó el $300 \%$, en un contexto donde el coeficiente de variación salarial fue del $192 \%$ (Fuente INDEC: 2019).

Asimismo, se procedió a un redireccionamiento de los subsidios, reorientándolos progresivamente a la demanda, en detrimento de los dirigidos a la oferta. Si bien esta tendencia ya se venía desarrollando desde el año 2012, cuando se introdujeron factores de demanda para el cálculo de las compensaciones (Resolución No 962/12 MIyT), los que se recalcularon en esa dirección en el año 2014 (Resolución 1482/14 MIyT), la nueva gestión se propuso eliminar totalmente los subsidios a la oferta para mayo de 2019.

El criterio para la distribución de las compensaciones incluyó: complemento tarifario por atributo social, compensaciones por boletos escolares y estudiantiles y boleto integrado, compensaciones por tarifa técnica, una suma por redistribución de ingresos y un nuevo factor de corrección para los kilómetros computables para las compensaciones tarifarias. ${ }^{38} \mathrm{La}$ implementación del Boleto Integrado en la RMBA, en el año 2018, consistió en aplicar descuentos escalonados ${ }^{39}$ según el número de viajes realizados dentro de un lapso de 120 minutos.

La medida pudo haber sido efectiva en términos de equidad, ya que quienes realizan mayor cantidad de trasbordos e invierten más tiempo en sus desplazamientos cotidianos pertenecen a los sectores de menores ingresos. Sin embargo, la aplicación de incrementos tarifarios por encima de la variación salarial, en un 
contexto económico regresivo con saldos crecientes en los índices de desocupación de la población, se vio fuertemente limitada en sus potenciales efectos progresivos, tanto para la población como para las finanzas públicas.

Entre las estrategias implementadas por los usuarios se advierte, en algunas líneas, una cantidad de viajes realizados con tarjetas SUBE que tienen atributo social (que implica descuentos del $55 \%$ ), lo que no coincide con la magnitud de los agrupamientos sociales que cumplen los requisitos para recibir el beneficio. Un informante clave del Ministerio de Transporte hipotetizaba en una entrevista que en la RMBA podrían estar vendiéndose tarjetas con atributo social por un precio mayor a la tarjeta sin atributo. Dicha situación constituye una estrategia emergente de la crisis general, por la cual los usuarios, principalmente aquellos que constituyen una demanda cautiva del transporte público, buscan paliar los impactos de los incrementos tarifarios pagando tarifas reducidas. Como contracara, lejos de lograrse una merma en el monto total de compensaciones para sostener el sistema, el erario público tuvo que afrontar una mayor presión al asignar mayores montos para su funcionamiento. De hecho, entre enero de 2016 y noviembre de 2018 las compensaciones para cubrir la diferencia entre tarifa técnica y comercial se incrementaron en un el 46.6 \% (Pérez y Sánchez, 2019). Dichas compensaciones implicaban, según datos de la ejecución presupuestaria anualizada a junio de 2019, 60.630 millones de pesos, de los cuales el $43.3 \%$ correspondía al Área Metropolitana de Buenos Aires.

La caída en la demanda de viajes sumó también un golpe al sistema. Fue del orden del $20 \%$ entre los años 2016 y $2018,{ }^{40}$ para todas las jurisdicciones (nacional, provincial y municipal).

En relación con la configuración de la oferta, a partir de 2016 reapareció como proceso la mortandad de empresas, que pasaron de 91 a 88, y emergieron dos nuevos grupos empresarios. Las empresas pertenecientes a grupos se incrementaron en 3 y las que no pertenecían a grupos disminuyeron en 6 (Pérez, 2019). Esta nueva reestructuración, producida al calor de quiebras, adquisiciones y nuevos gerenciamientos, permitió que hacia fines del año 2018 los dos grupos más grandes del mercado controlaran un cuarto del parque móvil de la jurisdicción nacional.

En la actualidad, el sistema de APP de la RMBA es prestado por 168 empresas privadas que operan un total de 380 líneas. Si se atiende al crecimiento de la oferta, no ha experimentado grandes transformaciones a lo largo del tiempo. El crecimiento poblacional de la RMBA, si bien ha arrastrado un incremento en la cantidad de viajes, no ha determinado un aumento de ellos en igual ritmo. ${ }^{41}$ La cantidad de líneas no ha mostrado una tasa de nacimiento relevante y las trazas no han variado sustantivamente, salvo por algunas modificaciones realizadas de facto por las empresas. Las nuevas demandas de movilidad se han visto satisfechas por modos de transporte no públicos. Entre 1970 y 2007, su uso mostró una caída sostenida pues perdió 27.6 puntos porcentuales en dicho lapso, mientras que el uso de automóvil particular creció prácticamente en la misma proporción (25.2\%) (Müller y Kralich, 2009).

Otro dato relevante es el cambio en los patrones de movilidad que tienden a desplazar las centralidades históricas, basadas en una direccionalidad de $\mathrm{CABA}$ hacia los partidos del conurbano y viceversa. Según datos proporcionados por Gutiérrez sobre la base del procesamiento de la Encuesta de Movilidad Domiciliaria del año 2010, el $47 \%$ de los viajes en la RMBA tiene un sentido periferia-periferia y un $39 \%$ se realiza dentro de los propios municipios. El flujo tradicional es de sólo un 14 \% (Gutiérrez, Entrevista PIUBAT, 2017).

Recientemente fue creada, en el marco del Ministerio de Transporte, una Unidad Ejecutora Especial Temporaria, de "Modernización de la red de colectivos del AMBA" (Resolución No 1154/2018, MT). La Unidad tiene entre sus funciones la tarea de planificar el sistema de rutas del APP de Jurisdicción Nacional, proponiendo la modificación de las actuales, entre otras competencias. Es la primera vez en la historia del colectivo que el Estado toma a su cargo plenamente la configuración de las rutas, hecho que debe entenderse, aunque no de manera excluyente, en el marco del fortalecimiento de capacidades basadas en el uso de la tecnología habilitada por el sistema SUBE. Como se ha mencionado, esta permite no sólo atender la 
configuración de la oferta de servicios de APP, sino que también posibilita planificar con una mirada global la movilidad de la RMBA.

Las condiciones están dadas; sin embargo, aún no se ha adelantado en ninguna decisión que avance en una reestructuración del sistema, ni mucho menos en articular las necesidades de modificación de rutas de APP desde una perspectiva integral, que incorpore las dinámicas globales de movilidad de la región y no sólo del sistema de colectivos urbanos.

\section{REFLEXIONES FINALES}

El derrotero de los 90 años de historia del colectivo en la RMBA arroja como constatación principal la ausencia de una planificación de la movilidad desde una mirada integral. Como se muestra a lo largo del artículo, el principal modo de transporte utilizado por la población metropolitana, se ha desarrollado principalmente anclado en las demandas de sus oferentes, los que, condicionados débilmente, aunque de manera creciente, por las acciones estatales, materializaron una oferta de servicios para la región, si bien extensa, muy heterogénea en cuanto a cobertura y conectividad. La emergencia a lo largo de los años de una movilidad estratificada, que replica las asimetrías socioeconómicas existentes en la población de la región, se comprende a la luz de esta falencia de largo alcance.

A lo anterior se suma la efectivización de decisiones de política asociadas a problemas macroeconómicos. Los ejemplos recientes son las políticas de compensaciones tarifarias en el marco de la crisis económica de inicios del milenio, basadas en consideraciones de equidad distributiva, y los recientes incrementos tarifarios y reducción de subsidios en el contexto de ajuste fiscal, apoyados en argumentos de eficiencia económica, que al no incorporar criterios anclados en las reales condiciones de la dinámica del sector ampliado del transporte, y del modo APP en particular, terminan por profundizar las falencias del sistema.

En el devenir de estos últimos años se han incrementado las capacidades estatales de una manera nunca antes vista en el campo. La gran cantidad de información del lado del sector público posibilita diagnósticos certeros sobre la movilidad de la Región y, en esta dirección, conforma una estructura de oportunidad favorable para la elaboración e implementación de políticas pensadas desde las necesidades del sector. Sin embargo, el riesgo es reificar el poder de las nuevas tecnologías en su potencial para brindar respuestas a demandas sociales. Sin la formación de recursos humanos altamente capacitados para esta tarea, y principalmente la existencia de una voluntad política tendiente a este objetivo, difícilmente se pueda avanzar hacia el horizonte de construir mejores condiciones de movilidad y accesibilidad para el conjunto social.

\section{REFERENCIAS}

Agencia de Transporte Metropolitano (2019). El transporte automotor en la Región Metropolitana de Buenos Aires. Recuperado a partir de: https://www.youtube.com/watch?v=gPF7D465W 1c\&feature=emb_title.

Asociación Argentina de Presupuesto (2014). Subsidios y compensaciones tarifarias en transporte. Recuperado a partir de: http://7mocielo.com.ar/images/Subsidios\%20al\%20transporte\%20ASAP.pdf.

Basualdo, E. (2013). Estudios de historia económica argentina desde mediados del siglo XX a la actualidad. Buenos Aires: Siglo XXI.

Di Ciano, M. (S/D). Evolución del precio del colectivo desde 1990 a 2015. Recuperado a partir de https://aduba.org.ar /wp-content/uploads/2016/07/EVOLUCION-DE-LA-TARIFA-DEL-BOLETO-DE-COLECTIVO-1.pdf

Domecq, R., Neri, N. y Saumet, C. (2014). La Comisión Nacional de Regulación del Transporte. Manuscrito inédito, Curso Estado y políticas públicas en Argentina y América Latina, Instituto de Transporte, Universidad Nacional de San Martín.

Gartner, A., Manzano, G. y Sánchez, J. (2011). Evolución del gasto de los hogares en transporte a partir de los resultados de las Encuestas de Gastos de los Hogares. Buenos Aires: Universidad Tecnológica Nacional. Centro Tecnológico 
de Transporte, Tránsito y Seguridad Vial. Recuperado a partir de http://c3t.fra.utn.edu.ar/wp-content/upload s/2011/06/Gasto-en-transporte-2011.pdf.

Gonzálvez, M. (noviembre, 2016). Subsidios al transporte. Taller participativo. Subsidios al Transporte. Programa Interdisciplinario de la Universidad de Buenos Aires sobre Transporte, Secretaría de Ciencia y Técnica, Universidad de Buenos Aires.

Gutiérrez, A. (2000). La producción del transporte público en la metrópolis de Buenos Aires. Cambios recientes y tendencias futuras. Revista EURE, XXVI(77), 109-136.

Gutiérrez, A. (2004). Concentración empresaria y eficiencia en el autotransporte urbano de Buenos Aires. Revista EURE, $X X X(91), 97-110$.

Gutiérrez, A. (2016). Reglamentación y plusganancias en el autotransporte urbano. El caso de Buenos Aires. Revista Transporte y Territorio, 16, 28-40.

Keblowski, W. (2018). Moving past sustainable mobility towards a critical perspective on urban transport. A right to the city-inspired analysis of fare-free public transport (PhD tesis), Vrije Universiteit Brussel and Université libre de Bruxelles. Brussels, Belgium.

Krantzer, G. y Sánchez, J. (1993). Cambio organizacional empresario en el autotransporte urbano de Buenos Aires. VI Congreso Latinoamericano de Transporte Público y Urbano. San José, Costa Rica.

Krantzer, G. y Sánchez, J. (1994). Una indagación sobre el transporte automotor en Buenos Aires: Maduración del sistema y concentración empresaria. Buenos Aires: Comisión Nacional de Regulación de Transporte.

Lozano, C. (2002). Catástrofe social en Argentina. La situación a junio del 2002. Buenos Aires: IEF, Instituto de Estudios y Formación-CTA, Central de Trabajadores Argentinos.

Ministerio de Transporte y Obras Públicas (1972). Estudio Preliminar de Transporte de la Región Metropolitana de Buenos Aires. Buenos Aires: Ministerio de Transporte y Obras Públicas.

Müller A. (2014). Evolución de la tasa de generación de viajes por modo (1997-2014). Manuscrito inédito.

Müller, A. y Kralich, S. (2009). Movilidad y cambios socio-económicos: el caso de la RMBA en las tres últimas décadas. $X V$ Congreso Latinoamericano de Transporte Público y Urbano. Buenos Aires.

Nahón, C. y Bonofiglio, N. (2007). ¿Entes de regulación o control? Imprecisiones del "moderno" esquema de regulación. Reflexiones y enseñanzas del caso argentino. Revista de Administración Pública (RAP), № 6/7, 1095-1120.

Páramo, M.S. (1991). La Corporación de Transportes de la Ciudad de Buenos Aires. Un fracaso hecho historia (Tesis de Doctorado), Facultad de Filosofía y Letras. Universidad Nacional de Cuyo.

Pérez, V. (2012). Acumulación privilegiada en el transporte metropolitano de pasajeros (1990-2003). En Castellani, A. (Coord.), Recursos Públicos, intereses privados (pp.161-191). Buenos Aires: UNSAM Edita.

Pérez, V. (2013). Estallidos de hostilidad en el transporte ferroviario de pasajeros. (Tesis de doctorado). Universidad de Buenos Aires, Facultad de Ciencias Sociales..

Pérez, V. (2019). Políticas públicas y acciones empresarias en el mercado de autotransporte público de pasajeros. Revista Realidad Económica, № 325, 9-34.

Pérez, V. y Sánchez, J (2019). La relación Estado-mercado en la configuración del autotransporte público colectivo de pasajeros en la Región Metropolitana de Buenos Aires (1928-2018). Revista Perspectivas de políticas públicas (en prensa).

PIUBAT (productor) (2017). Cortos PIUBAT. Productos audiovisuales para la discusión. Transporte y accesibilidad. Recuperado de http://cyt.rec.uba.ar/piubat/Paginas/Publicaci\%C3\%B3n-y-difusion.aspx.

Cámara Empresaria del Autotransporte de Pasajeros (1993). El Auto Colectivo. El transporte de personas por automotor. Suplemento Edición No 503, Fascículo 1 y 2. Buenos Aires: Cámara Empresaria del Autotransporte de Pasajeros.

Ruiz Díaz, S. (2003). Problemas del transporte en el Área Metropolitana de Buenos Aires. Buenos Aires: Academia Nacional de Ciencias Económicas. Instituto de Economía Aplicada “Dr. Vicente Vázquez Presedo". 
Ruiz Díaz, S., Scartaccini, A. y Trasmonte, A. (2008). 80 años en Colectivo. Reseña histórica del transporte de personas por automotor. Buenos Aires: Cámara Empresaria de Autotransporte de Pasajeros.

\section{Notas}

1 Desde una perspectiva de derechos, el transporte público constituye un servicio esencial en la medida en que las condiciones de su prestación afectan la consecución de otro conjunto de derechos, como el acceso a la educación, la salud, el trabajo y la recreación.

2 La base de empresas y grupos de autotransporte en la RMBA fue construida en el marco del Proyecto PICT-O 4803/16 (Proyectos de Investigación Científica y Tecnológica), financiado por la Agencia Nacional de Promoción Científica y Tecnológica, que se encuentra bajo mi dirección.

3 La ordenanza del 11 de junio de 1926 daba un plazo de 6 meses para que los ómnibus reemplazaran llantas de goma maciza por otras con neumáticos. Aquellas quedaban prohibidas para los ómnibus pero seguían estando permitidas para los camiones.

4 En esta dirección, la Compañía Anglo-Argentina [Ver abajo] solicitó y obtuvo el permiso para operar cinco líneas en la Capital, complementarias de su red tranviaria y de subterráneos. También obtuvo una concesión para 6 líneas en Avellaneda, que transfirió a la S.A.T.I.A., una empresa satélite. Con la adquisición de pequeñas empresas fundó otras subsidiarias (La Central y La Metropolitana), y fue ampliando la explotación de ómnibus hasta operar unas 25 líneas en la Capital y el Gran Buenos Aires. El Tranvía del Puerto también operó 3 líneas en la zona Sur y el F.C Central Argentino, dos en San Isidro (Ruiz Díaz e. al., 2008; Ruiz Díaz, 2003).

5 Solicitada de la Cía. Anglo-Argentina [Grafías diferentes] de Tranvías a la Municipalidad. La Nación y La Razón, 26/7/1928 (Páramo, 1991).

6 Los taxistas ya habían ensayado con éxito el transporte colectivo a los hipódromos, cobrando una tarifa fija a cada pasajero. En un contexto de merma de pasajeros y afectación de sus economías, decidieron ensayar el mismo sistema para algún recorrido permanente que les pudiera asegurar ingresos continuos (Ruiz Díaz et al., 2008, p. 16).

7 "En la Capital Federal tenían entre 17 y 36 asientos (...) Habían crecido y adquirido características que los asemejaban a los tranvías, como la plataforma trasera para el ascenso y descenso y la puerta delantera sólo para descender (...) Tenían ruedas traseras duales y carrocerías más altas y cuadradas, por cuyo interior se podía circular sin agacharse y el asiento del conductor estaba separado del salón por una mampara de madera y vidrio. Poseían talleres de uso exclusivo y camiones de auxilio propios y muchas veces explotaban varias líneas diferentes” (Ruiz Díaz, et al., 2008, p. 24)..

8 Algunos autores sugieren que la creación esta empresa se entiende en el marco de los acuerdos establecidos en el Pacto Roca-Runciman que en el año 1933 suscribieron Argentina e Inglaterra, el cual establecía -entre otros puntos- que las mayores compras británicas a nuestro país serían retribuidas con un trato benévolo. En este marco fue promovido el proyecto de "coordinación de transportes", que venía siendo demandado desde hacía años por la Empresa de Tranvías Anglo-Argentina (Ruiz Díaz et al., 2008).

9 Ibíd.

10 En concordancia con la creación de la CTBA, en el año 1937 se sancionó la Ley Nacional 12346, de Coordinación de Transportes, que reglamentaba los servicios de pasajeros y cargas por carreteras en la Capital Federal y los territorios nacionales, y los que recorrieran más de una provincia (Ruiz Díaz, 2003).

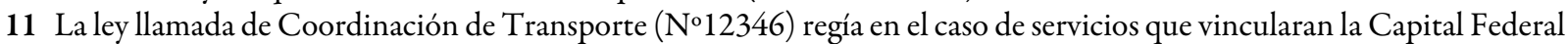
con una provincia. Las líneas de autotransporte colectivo en esta situación evitaron pasar a depender de la Corporación renunciando al tráfico en la ciudad (Estudio Preliminar de Transporte de la RMBA, Tomo 1, p. 175). Al respecto, y para casos específicos, se puede consultar el Primer Museo Virtual de Transporte Argentino en http://www.busarg.com.ar.

12 El sistema de trolebús consiste en un ómnibus eléctrico alimentado por una catenaria de dos cables superiores de los cuales toma la energía. A diferencia del tranvía, no utiliza vías especiales y tiene neumáticos en vez de ruedas de acero, lo que le aporta mayor flexibilidad en las maniobras.

13 Cámara Empresaria del Autotransporte de Pasajeros. Suplemento Edición No 503, septiembre-octubre de 1993. El Auto colectivo. El transporte de personas por automotor. Fascículo 2, p.16.

14 Ibíd., p. 24

15 En el mes de julio del año 1955 se constituyó la Intervención Liquidadora de la Empresa del Estado Transportes de Buenos Aires.

16 El 30 de abril de 1966 circularon por última vez los trolebuses en la ciudad de Buenos Aires.

17 En 1978 se otorgó el permiso para circular a la línea 193.

18 En esta forma empresarial, la empresa confía al socio o socios que la componen la explotación del vehículo, que es aportado por venta a crédito de la sociedad. Y aunque si lo necesita la empresa contrata personal de conducción, 
asumiendo las responsabilidades emergentes de la legislación laboral, el componente (socio) lo selecciona y reemplaza, tomando a su cargo las indemnizaciones derivadas de casos de despido. Así también, el componente solventa gastos de explotación, reservándose para sí los ingresos o formando un fondo que luego se distribuye mensualmente (o que se prorratea según los kilómetros recorridos por vehículo), o combinando ambos sistemas. En cuanto a los gastos correspondientes a cada vehículo, la sociedad formula un cargo a los componentes, que aplica como reducción del crédito del componente por la venta del vehículo, hasta su extinción total. Las inversiones también están a cargo de la empresa (Estudio Preliminar de Transporte de la RMBA, Tomo1, p. 178).

19 Entrevista a funcionario de la Dirección de Transportes durante la década del 70.

20 Ibíd.

21 Relevamiento realizado en el marco del Proyecto PICT-O 4803/16, "Estado y empresas en la Argentina de la posconvertibilidad. El caso del transporte colectivo de pasajeros del Área Metropolitana de Buenos Aires”. Directora: Dra. Verónica Pérez.

22 Esas 25 líneas licitadas, con un proceso que se concentró casi el 60 \% en los años 1998 y 1999, y un 25 \% hacia mediados de los 90, son una proporción insignificante respecto de lo que podría (y debería) haber sido un serio proceso licitatorio a lo largo de estos 50 años de preeminencia del APP. En este período se licitaron, entre otras, las líneas 6, 20, 25, 46, 49, $50,56,86,97,107,108,114,124,129,133,140 / 142,146,179,193$ y 195.

23 Según un entrevistado que se desempeñaba en la Dirección de Transporte durante el período referido, el organismo contaba con un cuerpo de inspectores de no más de 20 a 25 personas, encargadas de fiscalizar todo el transporte urbano e interurbano de pasajeros (PICTO 4803/16).

24 Benito Roggio e Hijos, asociada a COMETRANS (integrante del consorcio a cargo del ferrocarril Urquiza y de Metrovías), compró en 1998 dos líneas de autotransporte del corredor oeste. Otra empresa integrante de Ferrovías compró una línea alimentadora del Belgrano Norte (Gutiérrez, 2000).

Las cámaras empresarias del autotransporte alcanzaron una participación del $35 \%$ en el mercado ferroviario de pasajeros luego de las concesiones; en dos de los cuatro consorcios ganadores, la presidencia fue ocupada por referentes de las cámaras de autotransporte (Pérez, 2012).

25 Un estudio publicado por el Centro de Estudios de Transporte de la Universidad Tecnológica Nacional, sobre la evolución del gasto en transporte de los hogares, muestra que, mientras en el período 1985/86 los hogares destinaban el $29 \%$ del gasto en transporte al rubro transporte público, en el período 96/97 este guarismo se incrementó en 16.2 puntos y alcanzó el $45.2 \%$. (Gartner et al., 2011).

26 "De ahí surgieron los grandes empresarios actuales. Estos tipos que fueron comprándoles a sus compañeros. No es que tenían determinada actividad y que un día decidieron invertir en transporte. Eran ellos mismos que se fueron transformando en empresarios" (Entrevista a Funcionario Ministerio de Transporte, 2018).

27 Entrevista a informante clave del Ministerio de Transporte, 2019.

28 Sistema Único de Boleto Electrónico.

29 Resulta interesante ver que la norma internaliza, después de décadas de olvido (desde la renumeración de las líneas del APP), el hecho de que las diferentes jurisdicciones que operan en el AMBA forman parte de un todo para las necesidades de movilidad.

30 En el año 2014, 22 empresas de colectivos fueron imputadas por la justicia por declarar más kilómetros que los recorridos efectivamente, con el objeto de incrementar el monto de los subsidios recibidos. En ese entonces operaban en el sector 91 empresas. Al respecto, se puede consultar el trabajo de Pérez (2019).

31 Resolución 37 de la Secretaría de Transporte.

32 Fueron discriminadas según líneas del Distrito Federal, Suburbanas Grupo I, Suburbanas Grupo II, jurisdicción Provincial y jurisdicción Municipal. En el año 2015 se desagregarían en dos los grupos de tarificación de las líneas de jurisdicción municipal y el total de los segmentos de tarificación alcanzó el número de 7 (Resolución 1904 del MIyT).

33 Sobre la evolución del precio del colectivo entre 1990 y 2015, se puede consultar Di Ciano (S/D).

34 Por Resolución No 975 del año 2012 se dispuso un $40 \%$ de descuento en la tarifa para los usuarios que comportaran algún atributo social, entre los cuales quedaron incluidos: a) jubilados y pensionados, b) beneficiarios de la asignación universal por hijo, c) beneficiarios de la asignación por embarazo, d) beneficiarios del programa Jefes de Hogar, e) Personal de trabajo doméstico y $\mathrm{f}$ ) veteranos de guerra de la Guerra de Malvinas.

35 Según los autores del citado trabajo, el cumplimiento de las revisiones técnicas obligatorias y de los seguros en el Servicio Público Urbano de jurisdicción nacional es superior al 99,8\%.

36 El mismo entrevistado refería que, hasta los subsidios, muchas empresas tenían alta economía en negro, personal no registrado, conductores que sólo cobraban en blanco el salario mínimo, pagos atrasados por aportes patronales, compras no registradas. La tarifa no se peleaba tanto porque compensaban con una parte en negro. Hoy, si las empresas no tienen depositadas las contribuciones patronales y otros pagos que deben realizar, no se les paga el subsidio (Entrevista a funcionario del Ministerio de Transporte, 2019).

37 Barcelona (56\%), Madrid (60\%), Bruselas (68 \%), Ámsterdam (61\%), París (61\%) y Berlín (51 \%). 
38 Resolución 1144/2018 Ministerio de Transporte.

39 El descuento aplicado para viajes integrados, hasta un máximo de 5 trasbordos, es de $50 \%$ para el segundo viaje y de 75 $\%$ para los sucesivos hasta el quinto.

40 Elaboración propia, sobre la base de datos SUBE publicados en http//:argentina.gob.ar.

41 Entre 1970 y 2007 la población de la RMBA creció un 50 \%, pues pasó de 8.4 a 12 millones de habitantes; sin embargo, la cantidad de viajes lo hizo en un $15.9 \%$. 